ALVES, V.; MONTANARI, R.; CARVAlHO, M. P.; CORREA, A. R.; ROQUE, C. G. Atributos tecnológicos, stand e produtividade da cana-planta correlacionados com aspectos da fertilidade do solo em Chapadão do Céu (GO). Revista de Agricultura Neotropical, Cassilândia-MS, v. 1, n. 1, p. 75-91, jul./set. 2014.

\title{
ATRIBUTOS TECNOLÓGICOS, STAND E PRODUTIVIDADE DA CANA-PLANTA CORRELACIONADOS COM ASPECTOS DA FERTILIDADE DO SOLO
}

\section{VINICIUS ALVES ${ }^{1}$, RAFAEL MONTANARI ${ }^{1}$, MOREL DE PASSOS E CARVALHO ${ }^{1}$, ADRIANY RODRIGUES CORREA ${ }^{1}$, CASSIANO GARCIA ROQUE ${ }^{2}$}

${ }^{1}$ UNESP/Ilha Solteira, SP, vinicius.alves@cerradinho.com.br, rafamontana@hotmail.com, morel@agr.feis.unesp.br, adryany_rc@hotmail.com. ${ }^{2}$ UFMS, Chapadão do Sul, MS, cassiano.roque@ufms.br

RESUMO: A agricultura de precisão, que pode ser aplicada em qualquer etapa da produção de cana-de-açúcar, visa proporcionar maior produtividade, redução do impacto ambiental e melhor rendimento econômico pela aplicação correta dos insumos agrícolas. Objetivou-se com este trabalho caracterizar as zonas específicas de manejo do solo, empregando-se correlações lineares e espaciais entre atributos da cultura da cana-de-açúcar e atributos químicos de um Latossolo Vermelho-Amarelo distrófico, no sentido de indicar aquele que mais eficientemente esteja relacionado com o aumento da produtividade. $\mathrm{O}$ trabalho foi desenvolvido no ano agrícola de 2012/13, no município de Chapadão do Céu, Goiás, Brasil. Foram analisadas as correlações lineares e espaciais entre atributos da cana-de-açúcar e de alguns atributos químicos do solo, em duas profundidades $(0-0,25$ e $0,25-0,50 \mathrm{~m})$. Para isso, foi instalado um grid geoestatístico (230 m x $228 \mathrm{~m} ; 5,244 \mathrm{ha})$, onde foram alocados 121 pontos amostrais para coleta dos dados. Portanto, com o aumento do número de plantas por metro quadrado (stand) ocorreu também o aumento da produtividade de colmos de cana-deaçúcar. Os teores de fósforo do solo, por evidenciarem correlações lineares e espaciais com a produtividade de colmos, constituíram-se indicadores de zonas específicas de manejo do solo fortemente associadas à produtividade da cana-de-açúcar.

PALAVRAS-CHAVE: fósforo disponível, correlação espacial.

\section{TECHNOLOGICAL ATTRIBUTES, STAND AND SUGAR-CANE PRODUCTIVITY RELATIONSHIP WITH SOIL FERTILITY CHARACTERISTICS}

\begin{abstract}
Precision agriculture can be applied at any stage of the production of cane sugar, this practice aims to provide increased productivity, reduced environmental impact and improved economic performance through the correct application of inputs in the area. The objective of this study was to characterize the specific areas of soil management, using linear and spatial correlations between attributes of the culture of cane sugar and chemical properties of a Oxisol, in order to indicate that it more efficiently is related to the increased productivity. The work was developed in the agricultural year 2012/13, in Chapadão do Céu City, Goiás State, Brazil, we analyzed the linear and spatial correlations between attributes of cane sugar and some soil chemical properties at two depths (0 to 0.25 and 0.25 to $0.50 \mathrm{~m}$ ). For this, it was installed a geostatistical grid, $(230 \mathrm{~m} \times 228 \mathrm{~m} ; 5.244 \mathrm{ha})$, where were located 121 data collect points. With the increase in the number of plants per $\mathrm{m}^{2}$, increasing sugarcane yield of cane sugar per hectare occurs. The phosphorus soil, because they show correlations with sugarcane yield of cane sugar, are indicators of specific areas of soil strongly associated with productivity of cane sugar management.
\end{abstract}


KEY-WORDS: Available phosphorus, Sugar-cane technological attributes, Spatial correlation.

\section{INTRODUÇÃO}

A produção total de cana-de-açúcar no Brasil na safra 2014/15 foi estimada em 671,69 milhões de toneladas, com aumento de 2,0\% em relação à safra 2013/14 o que corresponde a uma área total de aproximadamente 9.130,1 mil hectares, distribuídas em todos os estados produtores. Nesta safra o Brasil terá um acréscimo na área estimado em 318,7 mil hectares, e Goiás está entre os quatro principais responsáveis por este aumento de área plantada com um acréscimo em cerca de 59,9 mil hectares. Goiás é o segundo maior produtor desta cultura entre os estados brasileiros, sendo responsável por cerca de 9,3\% (878,27 mil hectares) da área total cultivada no país (CONAB, 2013).

A importância na produção desta cultura, contudo, tem intensificado a utilização de máquinas agrícolas buscando uma melhor eficiência produtiva e um melhor rendimento econômico para o produtor. O aumento no uso dessas máquinas agrícolas tem gerado cada vez mais discussões a respeito da exploração agrícola sustentável. Assim como a degradação dos solos devido ao elevado uso de máquinas agrícolas no processo de produção (MONTANHA, 2011).

Para que o aumento se mantenha crescente no sistema de produção da cana-de-açúcar, o uso de fertilizantes e corretivos podem ser classificados como os insumos de maior importância, devido à capacidade que estes têm de influenciar a produtividade da cultura. Uma alternativa para a otimização do sistema é a adoção da agricultura de precisão (AP), que promove o conhecimento da variabilidade dos solos (CAMARGO et al., 2013).

$\mathrm{O}$ setor sucroalcooleiro vem investindo fortemente nessas tecnologias, estimativas informais apontam que $10 \%$ da área de cana-de-açúcar tem sido cultivada com AP, especificamente a tecnologia de aplicação em taxa variada. Muitas ainda estão em desenvolvimento, como a aplicação localizada de defensivos e o mapeamento da produtividade (MOLIN, 2001). No Estado de São Paulo, considerado o maior produtor de cana-de-açúcar do país, verificou-se que cerca de $56 \%$ das usinas fazem uso de algum tipo de tecnologia de agricultura de precisão, mostrando assim que esta é uma tecnologia bastante difundida no setor (CIRANI; MORAES, 2010).

A AP pode ser aplicada em qualquer etapa da produção de cana-de-açúcar, porém a forma mais conhecida é na aplicação de insumos a taxas variadas, tendo como base a realização de uma amostragem de solo realizada na área. O objetivo principal dessa aplicação é proporcionar maior produtividade ao produtor, redução do impacto ambiental e melhor rendimento econômico pela aplicação correta de insumos na área (MONTANHA, 2011).

Para que se possa realizar este tipo de aplicação utiliza-se a geoestatística que é uma das ferramentas da agricultura de precisão, permitindo realizar o estudo da variabilidade espacial dos atributos do solo, podendo assim indicar alternativas de manejo que propiciem a minimização do efeito da variabilidade dos atributos do solo sobre os cultivos. Assim, permite-se modelar e analisar a variabilidade espacial dos atributos de interesse agrícola gerando mapas de variabilidade espacial sem tendência e com variância mínima por meio da técnica de interpolação por krigagem (MONTANARI et al., 2011).

Sendo assim, objetivou-se com este trabalho caracterizar as zonas específicas de manejo do solo, empregando-se correlações lineares e espaciais entre atributos da cultura da cana-de-açúcar e atributos químicos de um Latossolo Vermelho-Amarelo distrófico, no 
sentido de indicar aquele que mais eficientemente esteja relacionado com o aumento da produtividade.

\section{MATERIAL E MÉTODOS}

A área deste estudo localiza-se na Fazenda Campo Bom, Quadra 2 (18³5’50.68 S; 52³6’34.02 W), parte do conjunto de terras da Usina Cerradinho, situada no município de Chapadão do Céu, Goiás, Brasil. Segundo a classificação de Köeppen, o tipo climático da região é Aw, caracterizado como tropical de estação seca, com estação chuvosa no verão e inverno seco. A região apresenta precipitação média anual de $1740 \mathrm{~mm}$, temperatura média anual ao redor de $23,2^{\circ} \mathrm{C}$ e déficit hídrico médio anual de $156 \mathrm{~mm}$. A altitude local predominante é de $800 \mathrm{~m}$, com relevo plano e declividade média inferior a $0,007 \mathrm{~m} / \mathrm{m}$. O solo da área experimental, classificado segundo preceitos da Embrapa (2013), é um LATOSSOLO VERMELHO-AMARELO Distrófico típico.

Para a implantação da cultura da cana-de-açúcar foi utilizada a variedade IACSP 955000, em área de plantio direto de culturas graníferas há mais de 10 anos, dessecada com glifosato na dose de $3,5 \mathrm{~L} \mathrm{ha}^{-1}$ do produto comercial. Em seguida, foi distribuído, a lanço calcário dolomítico na dose 3,6 $\mathrm{t} \mathrm{ha}^{-1}$ (PRNT 83\%), 2,4 t ha- ${ }^{-1}$ de gesso agrícola e 1,0 $\mathrm{t} \mathrm{ha}^{-1} \mathrm{de}$ AGROFFOS com dose fixa, que é um fertilizante fosfatado. Foi feita incorporação de corretivos e após foi realizado a subsolagem.

O plantio do talhão foi executado no dia 22/10/2012, no espaçamento entrelinhas de $1,50 \mathrm{~m}$. No plantio mecanizado utilizou-se $500 \mathrm{~kg} \mathrm{ha}^{-1}$ do fertilizante $08-28-20$, com $0,6 \%$ de Zn e $0,3 \%$ de $\mathrm{B}, 150 \mathrm{~L} \mathrm{ha}^{-1}$ de ácido húmico, fipronil na dose de $250 \mathrm{~g} \mathrm{ha}^{-1}$ e $0,5 \mathrm{~L} \mathrm{ha}^{-1}$ de piraclostrobina. A adubação de cobertura foi realizada aos 45 dias após a brotação da cultura, com $120,0 \mathrm{~kg} \mathrm{ha}^{-1}$ de cloreto de potássio. Para o controle de plantas invasoras foi aplicado 1,7 $\mathrm{L} \mathrm{ha}^{-1}$ de sulfentrazona e $1,6 \mathrm{~L} \mathrm{ha}^{-1}$ de clomazine em pré-emergência das plantas daninhas. Aos 60 dias após a brotação da cultura foi realizado o cultivo químico, junto com a operação de quebra-lombo. Utilizou-se 4,0 $\mathrm{kg} \mathrm{ha}^{-1}$ de ácido bórico $19 \%$ e 1,8 $\mathrm{kg} \mathrm{ha}^{-1}$ de tetuthiuron. A maturação da cana-de-açúcar foi induzida aos 20 dias antes da colheita, utilizando-se $20 \mathrm{~g} \mathrm{ha}^{-1}$ de sulfometuron metil, aplicado com avião agrícola. Para a coleta de dados, a cultura encontrava-se no primeiro corte, com 12 meses no campo.

Distribuíram-se simetricamente 121 pontos amostrais de forma a cobrir toda área do talhão escolhido, cuja malha geoestatística teve 230 m x 228 m, representando então 5,244 ha. Suas coordenadas geográficas foram convertidas em coordenadas planas, com o eixo cartesiano $\mathrm{Y}$ coincidente à longitude, enquanto que, o $\mathrm{X}$, à latitude. Cada ponto amostral representou um quadrado de 433,39 $\mathrm{m}^{-2}$, com o lado tendo em média $20,82 \mathrm{~m}$.

Para o posicionamento em campo, as coordenadas foram inseridas no aparelho GPS topográfico geodésico, com receptor GS10 L1/L2, com projeção UTM (universal transverse mercartor) e Datum SAD 69, na zona 22S, com precisão milimétrica devido à correção instantânea em duas fases, por meio da tecnologia RTK (real time kinematic).

As amostragens foram realizadas em 21/10/2013. Para a coleta dos atributos trabalhados, da planta e do solo, foram definidas duas linhas de $3 \mathrm{~m}$ no sentido de plantio, totalizando uma área de $9 \mathrm{~m}^{2}$ no entorno do ponto amostral, uma vez que o espaçamento entre linhas foi de 1,50 m. Para a obtenção do atributo população de plantas (STD), expresso em pl $\mathrm{m}^{-2}$, utilizou-se uma trena para marcar $3 \mathrm{~m}$ lineares e assim executou-se a contagem do número de colmos industrialmente viáveis por ponto. Para a produtividade de colmos de canade-açúcar (PRO), expressa em $\mathrm{t}$ ha $^{-1}$, utilizou-se uma balança eletrônica portátil com capacidade de $100,00 \mathrm{~kg}$ (+/- 0,04 kg). Os colmos foram organizados em feixes, pesados e 
contados para a obtenção da massa de colmos por ponto. Após a coleta dos dados de PRO, em uma planilha Excel, realizou-se a extrapolação da área útil de $9 \mathrm{~m}^{2}$ para 1 ha.

Em relação aos atributos da planta, a produtividade de colmos (PRO), expressa em t ha $^{-1}$, foi obtida pela pesagem dos colmos contidos numa área útil do de $9 \mathrm{~m}^{2}$, sendo duas linhas de $3 \mathrm{~m}(3 \mathrm{~m} \times 3 \mathrm{~m})$ por ponto amostral, a população de plantas (STD) do ponto amostral, com área útil de $9 \mathrm{~m}^{2}$, onde seus valores foram expressos em plantas por metro quadrado. Os atributos tecnológicos, açúcares totais recuperáveis (ATR), percentual de sólidos solúveis totais (BRI), percentual de sacarose (POL), percentual de pureza (PUR) e percentual de fibra (FIB), porcentagem de açúcares redutores do caldo (ARC), foram determinados no laboratório da Usina de Álcool e Açúcar, (PCTS - Pagamento da Cana-de-açúcar pelo Teor de Sacarose) conforme metodologia proposta pelo Consecana (2006).

Os atributos químicos do solo pesquisados foram os teores de fósforo $(\mathrm{P})$ e de matéria orgânica (MO), valor do $\mathrm{pH}$ em $\mathrm{CaCl}_{2}(\mathrm{pH})$, capacidade de troca catiônica (T), soma de bases (SB), saturação por bases (V\%) e saturação por alumínio (m\%). Para a obtenção dos atributos do solo, foram coletadas amostras deformadas individualmente no entorno do ponto amostral, nas profundidades de 0-0,25 $\mathrm{m}$ e 0,25-0,50 m, com um trado de caneca (diâmetro $=0,08 \mathrm{~m}$, altura $=0,20 \mathrm{~m}$, volume $=1,005 \cdot 10^{-3} \mathrm{~m}^{3}$ ). Obteve-se a terra fina seca ao ar (TFSA) passando-a por uma peneira com malha de 2,0 mm, sendo as análises químicas realizadas no Laboratório de Fertilidade do Solo Athenas de Jaboticabal (SP). Na caracterização química do solo foram determinados, a acidez ativa $\left(\mathrm{pH}\right.$ em $\mathrm{CaCl}_{2}$ ), obtida potenciometricamente utilizando-se a relação 1:2,5 (solo: $\mathrm{CaCl}_{2}$ ). $\mathrm{O}$ fósforo disponível (P) foi extraído pelo método da resina trocadora de íons, proposta por Raij et al. (2001); os valores V\% e m\% foram quantificados respectivamente pelas seguintes expressões: V\% $=(\mathrm{S} / \mathrm{T}) \times 100 ; \mathrm{m} \%=\left(\mathrm{Al}^{+3} / \mathrm{Al}^{+3}+\mathrm{S}\right) \times 100$, onde $\mathrm{V} \%$ e $\mathrm{m} \%$ são, respectivamente, a saturação por bases e a saturação por alumínio, expressas em porcentagem (\%). A determinação da matéria orgânica (MO) foi realizada por combustão a seco, utilizando-se um analisador Leco CN-2000, em amostras moídas e peneiradas a 60 meshes. Posteriormente, calculadas a capacidade de troca catiônica (T) e a soma de bases (SB), segundo procedimentos descritos por Raij et al. (2001).

Para cada atributo estudado foi efetuada a análise descritiva auxiliada pela estatística clássica utilizando-se o SAS (SCHLOTZHAVER; LITTEL, 1997). Também foi efetuada a análise da distribuição de frequência por meio do teste de Shapiro e Wilk (1965) com 1\% probabilidade de erro. A modelagem geoespacial foi realizada com o programa $\mathrm{GS}^{+} 7.0\left(\mathrm{GS}^{+}\right.$, 2004). A técnica de krigagem foi utilizada para estimar valores nos locais não amostrados por ser um estimador linear não enviesado. Uma vez determinados os valores, para os locais não amostrados, pela krigagem, foram construídos os mapas de isolinhas utilizando-se o programa $\mathrm{GS}^{+}\left(\mathrm{GS}^{+}, 2004\right)$, que emprega os mesmos valores estimados por meio da técnica de krigagem para determinação e localização das isolinhas; desta maneira, os mapas representam linhas bem definidas e embasadas em um algoritmo de regressão linear, conforme descrito por Siqueira et al. (2008). A análise do avaliador da dependência espacial (ADE) foi efetuada conforme a Equação $1\left(\mathrm{GS}^{+}, 2004\right)$ :

$\mathrm{ADE}=\left[\mathrm{C} /\left(\mathrm{C}+\mathrm{C}_{\mathrm{o}}\right)\right] .10$

onde: ADE é o avaliador da dependência espacial; $\mathbf{C}$, a variância estrutural; e $\mathbf{C}+\mathbf{C}_{0}$, o patamar. A interpretação proposta para o $\mathrm{ADE}$ foi a seguinte: a) $\mathrm{ADE}<20 \%=$ variável espacial de muito baixa dependência (MB); b) $20 \% \leq \mathrm{ADE}<40 \%=$ baixa dependência (BA); c) $40 \% \leq \mathrm{ADE}<60 \%=$ média dependência (ME); d) $60 \% \leq \mathrm{ADE}<80 \%=$ alta dependência (AL) e $80 \% \leq \mathrm{ADE}<100 \%=$ muito alta dependência (MA) (DALCHIAVON et al., 2012). 


\section{RESULTADOS E DISCUSSÃO}

\section{Análise descritiva de atributos tecnológicos}

De acordo com Pimentel Gomes; Garcia (2002), a variabilidade de um atributo pode ser classificada segundo a magnitude de seu coeficiente de variação (CV). Suas classes foram determinadas como baixa $(\mathrm{CV} \leq 10 \%)$, média $(10 \%<\mathrm{CV} \leq 20 \%)$, alta $(20 \%<\mathrm{CV} \leq 30 \%)$ e muito alta $(\mathrm{CV}>30 \%)$.

De acordo com a Tabela 1, para produtividade de colmos de cana-de-açúcar por hectare (PRO), número de plantas por $\mathrm{m}^{2}$ (STD), porcentagem de sólidos solúveis totais (BRI), porcentagem de sacarose (POL), porcentagem de pureza (PUR), porcentagem de Fibras (FIB), porcentagem de açúcares redutores do caldo (ARC), $\mathrm{pH}$ do caldo (pHC) e açúcares totais recuperáveis (ATR), foram encontradas respectivamente média variabilidade $(18,43 \%)$, média variabilidade $(16,31 \%)$, baixa variabilidade $(3,34 \%)$, baixa variabilidade $(3,94 \%)$, baixa variabilidade $(2,62 \%)$, baixa variabilidade $(7,92 \%)$, media variabilidade $(11,6 \%)$, baixa variabilidade $(2,15 \%)$ e baixa variabilidade $(3,94 \%)$.

Souza et al. (2010a) também encontraram média variabilidade para produtividade de colmos $(18,51 \%)$, o atributo ATR apresentou baixa variabilidade, corroborando Dutra Filho et al. (2011) trabalhando com cana-de-açúcar em um Argissolo Vermelho-Amarelo. A distribuição de frequência normal é a ideal para um estudo estatístico (análise de regressão e/ou geoestatística), ainda que na geoestatística, mais importante que a normalidade dos dados é a ocorrência ou não do efeito proporcional em que a média e a variância dos dados não sejam constantes na área de estudo (DALCHIAVON et al., 2012).

Os atributos de planta PRO, STD, BRI, POL, FIB e ATR, apresentaram distribuição de frequência do tipo normal, com valores do teste de normalidade de Shapiro; Wilk (1965), variando de 0,187 a 0,428 a $5 \%$ de probabilidade (Tabela 1). Esse tipo de distribuição para atributos de origem biológica é comum, assim estes atributos podem ser representados por seus valores médios. A média do atributo PRO (Tabela 1) foi $112,12 \mathrm{t} \mathrm{ha}^{-1}$ valor acima da média nacional $\left(74,10 \mathrm{t} \mathrm{ha}^{-1}\right)$, da região centro-oeste $\left(72,52 \mathrm{t} \mathrm{ha}^{-1}\right)$ e do estado de Goiás $(74,86$ $\left.\mathrm{t} \mathrm{ha}^{-1}\right)(\mathrm{CONAB}, 2013)$. A alta produtividade pode ser explicada pelo fato da cana planta estar no seu primeiro ano produtivo com seu melhor potencial. Para o atributo ATR observa-se uma média de $160,68 \mathrm{~kg} \mathrm{t}^{-1}$ superior ao referencial nacional $\left(135,7 \mathrm{~kg} \mathrm{t}^{-1}\right)$ de acordo com Conab (2013) e ao encontrado por Carvalho et al. (2011) trabalhando com cana-de-açúcar sob plantio direto em Rio Brilhante-MS (117,57 $\left.\mathrm{kg} \mathrm{t}^{-1}\right)$.

A média da porcentagem de sacarose foi de $16,69 \%$, valor dentro da faixa de referência recomendada por Lavanholi (2008) (14 a 24\%), e corrobora Correia et al. (2014) que obtiveram uma média de $18,12 \%$. Assim, como a média de FIB que se encontra dentro do padrão recomendado por Scapari e Beuclair (2008) que comentaram que o valor de fibras na cultura pode variar de 9 a 20\% durante a safra. Já em relação aos valores de PUR e BRI, observou-se, respectivamente os valores de 86,60 e 22,52, valores acima do encontrado por Dalchiavon et al. (2014) que obtiveram valores de 79,3 e 15,25 respectivamente e semelhante aos encontrado por Correia et al. (2014), trabalhando em um Argissolo Vermelho Amarelo com valores de 87,16 e 20,62.

O atributo STD apresentou uma média de 8,07 plantas por $\mathrm{m}^{2}$ (Tabela 1). Para Silva (2008) a recomendação para um bom estande de plantas de cana-de-açúcar é de 10 a 12 plantas por metro. Porém podem sofrer interferência de acordo com as variáveis utilizadas e de fatores climáticos. 


\section{Análise descritiva de atributos do solo}

Para os atributos químicos do solo, os valores do coeficiente de variação (CV \%) oscilaram entre baixo e muito alto (Tabelas 2 e 3). Constatou-se baixa variabilidade para pH1 e pH2 $(9,40 ; 8,77 \%)$. Esse baixo coeficiente de variação indica que o pH não teve muita variação no solo. A variabilidade desses dados apresentaram comportamento semelhante aos de Souza et al. (2010a), que encontraram para pH1 e pH2 de 7,69 e 7,05\%, respectivamente. Contudo, para a MO1 e MO2 foi obtida média variabilidade $(13,96 ; 16,20 \%)$ e os resultados obtidos por Souza et al. (2010a) discordaram dos do presente trabalho, pois obtiveram alta variabilidade. Souza et al. (2010b) em um Latossolo Vermelho distrófico encontraram valores próximos para os atributos teor de matéria orgânica MO1 e MO2 de 14,05 e 19,89\%.

A saturação por base (V\%1 e V\%2) apresentou alta variabilidade (22,09; 26,65\%), discordando dos resultados encontrados por Souza et al. (2010a) em um Argissolo VermelhoAmarelo e Souza et al. (2004) em um Latossolo Vermelho eutroférrico, ambos com média variabilidade. Segundo Vanni (1998), coeficiente de variação maior que 35\% revela que a série é heterogênea, e a média tem pouco significado. Assim, m\%1 e m\%2, apresentaram muito alta variabilidade, sendo respectivamente 130,32 e 100,53\%.

Para P1 e P2 foram constatados coeficientes de variação 47,81; 51,84\%, respectivamente (Tabela 2 e 3). Oliveira et al. (2013) também encontraram variabilidade muito alta para fósforo. De acordo com Camargo et al. (2013) essa grande amplitude de variação dos teores de $\mathrm{P}$ está relacionada à forma de aplicação do fertilizante, que geralmente é realizada no sulco de plantio e na linha, que apresenta teores variáveis de $\mathrm{P}$ e a pouca mobilidade do $\mathrm{P}$, o que pode causar acúmulo desse elemento, justificando os valores mais altos. Já os valores mais baixos podem estar relacionados ao fenômeno de adsorção desse nutriente aos óxidos de Fe e Al.

Pode-se verificar nas tabelas 2 e 3 as médias para pH1 e pH2 (5,31 e 4,86); valores estes próximos ao encontrado por Souza et al. (2007) em um Latossolo Vermelho eutroférrico. Para P1 e P2 podem-se observar médias $\left(34,51 ; 12,82 \mathrm{mg} \mathrm{dm}^{-3}\right)$ respectivamente, Souza et al. (2007) constataram valores de $26,4 \mathrm{mg} \mathrm{dm}^{-3}$ na profundidade $0,00-0,20 \mathrm{~m}$. Para a MO1 e MO2 as médias obtidas de 24,$11 ; 18,32 \mathrm{~g} \mathrm{dm}^{-3}$ foram superiores as encontradas por Souza et al. (2010a) sendo 15,$45 ; 15,18 \mathrm{~g} \mathrm{dm}^{-3}$, respectivamente.

Os valores médios de Ca1, Ca2, Mg1 e Mg2 (31,44; 17,21; 10,0 e 6,53) encontrados foram semelhantes aos encontrados por Souza et al. (2004), trabalhando em um Latossolo Vermelho eutroférrico que verificou médias de 37,6;24,3; 12,3 e 6,5 respectivamente. Já os valores V\% verificados no presente trabalho foram maiores $(64,11)$ na primeira profundidade e inferiores na segunda profundidade (50 e 51) em relação aos encontrados por Souza et al. (2004) $(59,3$ e 57,3) na primeira e segunda produtividade respectivamente.

\section{Matriz de Correlação}

$\mathrm{Na}$ tabela 4 estão apresentadas as correlações lineares entre os atributos da planta, onde pode se observar a relação direta entre PRO x STD onde evidenciou que com o aumento da STD houve um aumento da PRO. As demais correlações significativas entre os atributos estão expressas na tabela 4. Os atributos de fertilidade ressaltaram a importância da matéria orgânica no solo, onde apresentou correlação significativa positiva nas duas profundidades com $\mathrm{P}, \mathrm{Ca}, \mathrm{Mg}, \mathrm{SB}, \mathrm{T}$ e V\% e correlações negativas em ambas as profundidades com o Al e $\mathrm{m}$; tais correlações indicam que a MO contribui de forma significativa para a manutenção da fertilidade, mostrando que este é um atributo de grande importância para a conservação do potencial produtivo deste solo (Tabela 4). 
Na profundidade 1 (Tabela 5), a produtividade não apresentou correlação significativa com nenhum dos atributos de solo, e na profundidade 2 (Tabela 6) apresentou correlações significativas, porém baixas, com o P $\left(0,199^{*}\right)$ e $\mathrm{H}+\mathrm{Al}(-0,179 *)$. Souza et al. (2010a) afirmaram que a baixa correlação da produtividade de culturas com atributos do solo tem sido observada em diversas pesquisas (CERRI; MAGALHÃES, 2012).

A correlação encontrada entre e PRO e o P apresentou comportamento direto, sendo assim, 19,9 \% da variância da PRO é explicada pela variância do P2, com o aumento do P2, haverá também um aumento da produtividade (PRO). E a PRO negativamente correlacionada com o H + Al discorda dos resultados encontrados por Cerri e Magalhães (2012), que encontraram uma correlação positiva $(0,32)$ entre estes atributos.

\section{Semivariogramas}

Na tabela 7 estão apresentados os parâmetros dos semivariogramas simples e cruzados ajustados para os componentes tecnológicos da cana-de-açúcar, bem como para os atributos químicos do solo no qual o experimento foi instalado. Assim, ficou atestado que, com exceção de BRI, FIB, Al1 e m\%1 que apresentaram efeito pepita puro, todos os demais atributos mostraram dependência espacial.

Os atributos da cana apresentaram dependência espacial variando de média a muito alta, onde STD, PUR e ARC apresentaram ADE médio $(54,7 \%, 50 \%$ e 50,1\%) e os atributos PRO, POL, PHC e ATR mostraram dependência espacial muito alta $(90,4 \%, 89,8 \%$, 92,4\%, 91\%) (Tabela 7), cujos modelos de semivariogramas foram do tipo exponencial. Em relação aos atributos de solo a dependência espacial também variou de média a muito alta. $\mathrm{O}$ $\mathrm{Ca}(50 \%$ e $50 \%)$ e $\mathrm{Mg}(52,1 \%$ e $56,6 \%)$ em ambas as profundidades apresentaram variabilidade média, e S2 e V\%2 apresentaram dependência alta $(68,4 \%$ e $61,8 \%)$ e os demais atributos apresentaram dependência espacial muito alta ( $80 \% \leq \mathrm{ADE}<100 \%$ ), cujos modelos de semivariograma foram do tipo exponencial. Os valores de ADE altos indicam que se tem melhor estrutura espacial e que maior precisão pode ser obtida no mapeamento das propriedades estudadas usando técnicas de geoestatística como a krigagem (KRAVCHENKO et al., 2006).

$\mathrm{O}$ valor do $\mathrm{r}^{2}$ determinado de 0,826 para $\mathrm{PRO}$, indicou ser esse atributo o de melhor ajuste semivariográfico, com ADE classificado em muito alto $(90,4 \%)$ e o modelo ajustado foi do tipo exponencial com alcance de $87,3 \mathrm{~m}$. Montanari et al. (2008) trabalhando em um Latossolo Vermelho distrófico encontraram valores de $\mathrm{r}^{2}$ de 0,68 e o modelo se ajustou ao modelo esférico com alcance de $259 \mathrm{~m}$.

$\mathrm{Na}$ análise das cokrigagens (Tabela 7), o ajuste $\mathrm{PRO}=\mathrm{f}(\mathrm{P} 2)$, evidenciou que $84,1 \%$ da variabilidade espacial do atributo PRO pode ser explicada pela variabilidade do P2. De acordo com Camargo et al. (2013) se a aplicação de fertilizantes for feita considerando apenas a média dos teores de $\mathrm{P}$, em alguns locais podem ser sub ou superdimensionada. Grande parte da aplicação de fertilizantes fosfatados é realizada sem considerar a variabilidade espacial dentro de uma área de manejo, o que causa aumento no custo do processo produtivo, uma vez que áreas com pouca necessidade de $\mathrm{P}$ recebem as mesmas quantidades que as com deficiência (MARQUES JÚNIOR et al., 2008).

Buscando minimizar essa prática pode-se recomendar práticas para as zonas de manejo, nas quais o P2 apresentou seus menores valores, visando elevar a produtividade de colmos de cana-de-açúcar por hectare (Figura 1d). Sendo assim, do ponto de vista espacial, o P2 apresentou-se como um satisfatório indicador da qualidade do solo estudado, quando considerado a PRO. 


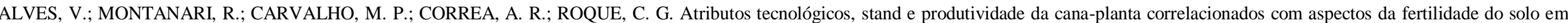
Chapadão do Céu (GO). Revista de Agricultura Neotropical, Cassilândia-MS, v. 1, n. 1, p. 75-91, jul./set. 2014.

Tabela 1. Análise descritiva inicial de atributos da cultura da cana-de-açúcar.

\begin{tabular}{|c|c|c|c|c|c|c|c|c|c|c|}
\hline \multirow{3}{*}{ Atributo } & \multicolumn{10}{|c|}{ Medidas estatísticas descritivas } \\
\hline & \multirow{2}{*}{ Média } & \multirow{2}{*}{ Mediana } & & & \multirow{2}{*}{$\begin{array}{l}\text { Desvio } \\
\text { Padrão }\end{array}$} & \multicolumn{3}{|c|}{ Coeficiente } & \multicolumn{2}{|c|}{$\begin{array}{l}\text { Probabilidade } \\
\text { do teste }^{(b)}\end{array}$} \\
\hline & & & Máximo & Mínimo & & Variação (\%) & Curtose & Assimetria & $\operatorname{Pr}<w$ & DF \\
\hline \multicolumn{11}{|c|}{ Atributos da planta } \\
\hline $\operatorname{PRO}\left(\mathrm{t} \mathrm{ha}^{-1}\right)$ & 112,12 & 111,67 & 170,00 & 47.78 & $20.66^{1}$ & 18.43 & 0.178 & -0.272 & 0,4277 & $\mathrm{NO}$ \\
\hline $\operatorname{STD}\left(\mathrm{pl} \mathrm{m}^{-2}\right)$ & 8,07 & 8,11 & 11,00 & 3,56 & 1,31 & 16,31 & 0,492 & $-0,402$ & 0,2278 & $\mathrm{NO}$ \\
\hline BRI $(\%)$ & 22,52 & 22,47 & 24,37 & 20,49 & 0,75 & 3,34 & 0,099 & 0,071 & 0,1838 & $\mathrm{NO}$ \\
\hline POL $(\%)$ & 16,69 & 16,70 & 18,33 & 14,91 & 0,66 & 3,94 & 0,167 & 0,042 & 0,1198 & $\mathrm{NO}$ \\
\hline PUR (\%) & 86,60 & 86,57 & 94,40 & 81,93 & 2,27 & 2,62 & 0,550 & 0,832 & $<0,0001$ & IN \\
\hline FIB $(\%)$ & 11,24 & 11,27 & 13,49 & 9,35 & 0,89 & 7,92 & $-0,347$ & $-0,054$ & 0,2089 & NO \\
\hline $\operatorname{ARC}(\%)$ & 0.67 & 0.67 & 0,83 & 0.40 & 0,08 & 11.60 & 0,636 & $-0,847$ & $<0,0001$ & IN \\
\hline $\mathrm{pHC}(\%)$ & 5.32 & 5.30 & 5.50 & 5.10 & 0.11 & 2.15 & -0.873 & -0.020 & $<0,0001$ & IN \\
\hline $\operatorname{ATR}\left(\mathrm{kg} \mathrm{t}^{-1}\right)$ & 160,68 & 160,68 & 176,55 & 143,61 & 6,33 & 3,94 & 0,160 & 0,073 & 0,1869 & $\mathrm{NO}$ \\
\hline
\end{tabular}

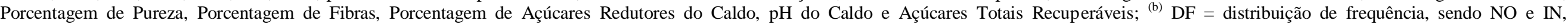
respectivamente do tipo normal e indeterminado.

Tabela 2. Análise descritiva inicial de atributos químicos coletados nas camadas do solo de 0,00-0,25 m de um Latossolo Vermelho-Amarelo distrófico de Chapadão do Céu, GO.

\begin{tabular}{|c|c|c|c|c|c|c|c|c|c|c|}
\hline \multirow{3}{*}{ Atributo } & \multicolumn{10}{|c|}{ Medidas estatísticas descritivas } \\
\hline & \multirow{2}{*}{ Média } & \multirow{2}{*}{ Mediana } & \multicolumn{2}{|l|}{ Valor } & \multirow{2}{*}{$\begin{array}{l}\text { Desvio } \\
\text { Padrão }\end{array}$} & \multicolumn{3}{|l|}{ Coeficiente } & \multicolumn{2}{|c|}{$\begin{array}{l}\text { Probabilidade } \\
\text { do teste }^{(\mathrm{b})}\end{array}$} \\
\hline & & & Máximo & Mínimo & & Variação (\%) & Curtose & Assimetria & $\operatorname{Pr}<w$ & DF \\
\hline \multicolumn{11}{|c|}{ Atributos do solo } \\
\hline $\mathrm{pH} 1$ & 5.31 & 5.30 & 6.60 & 4,30 & 0.50 & 9.40 & -0.556 & 0,125 & 0,1812 & NO \\
\hline $\operatorname{MO1}\left(\mathrm{g} \mathrm{dm}_{2}^{-3}\right)$ & 24,11 & 23,40 & 32,70 & 17,60 & 3,37 & 13,96 & 0,013 & 0,623 & 0,0011 & IN \\
\hline $\mathrm{P} 1\left(\mathrm{mg} \mathrm{dm}{ }^{-3}\right)$ & 34,51 & 32,20 & 83,40 & 4,50 & 16,50 & 47,81 & $-0,286$ & 0,583 & 0,0021 & IN \\
\hline $\left.\mathrm{S} 1(\mathrm{mg} \mathrm{dm})^{-3}\right)$ & 19,87 & 17,40 & 49,40 & 7,60 & 9,10 & 45,79 & 0,823 & 1,068 & $<0,0001$ & IN \\
\hline $\mathrm{Ca} 1\left(\mathrm{mmol}_{\mathrm{c}} \mathrm{dm}^{-}\right.$ & 31,44 & 30,00 & 83,00 & 8,00 & 14,09 & 44,81 & 1,876 & 1,014 & $<0,0001$ & IN \\
\hline $\operatorname{Mg} 1\left(\mathrm{mmol}_{\mathrm{C}}\right.$ & 10,00 & 10,00 & 25,00 & 2,00 & 4,63 & 46,35 & 1,026 & 0,751 & 0,0004 & IN \\
\hline
\end{tabular}




\begin{tabular}{|c|c|c|c|c|c|c|c|c|c|c|}
\hline $\mathrm{K} 1\left(\mathrm{mmol}_{\mathrm{c}} \mathrm{dm}^{-}\right.$ & 1,28 & 1,30 & 2,30 & 0,50 & 0,371 & 29,07 & $-0,240$ & 0,182 & 0,2113 & $\mathrm{NO}$ \\
\hline $\mathrm{All}\left(\mathrm{mmol}_{\mathrm{c}} \mathrm{dm}^{-}\right.$ & 0,85 & 0,60 & 3,10 & 0,00 & 0,68 & 79.79 & 1,419 & 1,405 & $<0,0001$ & IN \\
\hline $\mathrm{H}+\mathrm{All}\left(\mathrm{mmol}_{\mathrm{c}}\right.$ & 21,83 & 19,50 & 45,00 & 9,00 & 7,40 & 33,88 & 0,293 & 0,996 & $<0,0001$ & IN \\
\hline $\mathrm{SB} 1\left(\mathrm{mmol}_{\mathrm{c}} \mathrm{dm}^{-}\right.$ & 40,17 & 40,10 & 87,10 & 11,3 & 15,20 & 37,83 & $-0,347$ & 0,253 & 0,1608 & NO \\
\hline $\mathrm{T} 1\left(\mathrm{mmol}_{\mathrm{r}} \mathrm{dm}^{-3}\right)$ & 64.59 & 63.80 & 124.40 & 29.5 & 17.09 & 26.46 & 1.879 & 0,947 & 0,0001 & IN \\
\hline $\mathrm{V} 1(\%)$ & 64,11 & 67,90 & 87,70 & 26,10 & 14,16 & 22,09 & $-0,440$ & $-0,602$ & 0,0002 & IN \\
\hline $\mathrm{m} 1(\%)$ & 3.03 & 1,40 & 19.30 & -1.80 & 3.96 & 130,32 & 4.064 & 2,128 & $<0,0001$ & IN \\
\hline
\end{tabular}

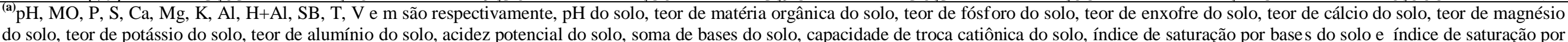
alumínio do solo, coletados nas camadas do solo de $0,00-0,25 \mathrm{~m} ;{ }^{\left({ }^{6}\right)} \mathrm{DF}=$ distribuição de frequência, sendo NO e IN, respectivamente do tipo normal e indeterminado.

Tabela 3. Análise descritiva inicial de atributos químicos coletados nas camadas do solo de 0,25-0,50 m de um Latossolo Vermelho-Amarelo distrófico de Chapadão do Céu, GO.

\begin{tabular}{|c|c|c|c|c|c|c|c|c|c|c|}
\hline \multirow[t]{3}{*}{ Atributo ${ }^{(a)}$} & \multicolumn{10}{|c|}{ Medidas estatísticas descritivas } \\
\hline & \multirow[t]{2}{*}{ Média } & \multirow[t]{2}{*}{ Mediana } & \multicolumn{2}{|c|}{ Valor } & \multirow[t]{2}{*}{ Desvio Padrão } & \multicolumn{3}{|c|}{ Coeficiente } & \multicolumn{2}{|c|}{ Prob.do teste ${ }^{(b)}$} \\
\hline & & & Máximo & Mínimo & & Variação (\%) & Curtose & Assimetria & $\mathrm{Pr}<\mathrm{w}$ & $\mathrm{DF}$ \\
\hline \multicolumn{11}{|c|}{ Atributos do solo } \\
\hline $\mathrm{pH} 2$ & 4,86 & 4,80 & 6,40 & 4,10 & 0,43 & 8,77 & 1,309 & 1,073 & $<0,0001$ & IN \\
\hline $\mathrm{MO} 2\left(\mathrm{~g} \mathrm{dm}^{-3}\right)$ & 18,32 & 18,00 & 27,20 & 12,20 & 2,97 & 16,20 & 0,071 & 0,271 & 0,1199 & NO \\
\hline $\left.\mathrm{P} 2(\mathrm{mg} \mathrm{dm})^{-3}\right)$ & 12,82 & 11,50 & 38,00 & 3,10 & 6,65 & 51,84 & 2,376 & 1,438 & $<0,0001$ & IN \\
\hline $\left.\mathrm{S} 2(\mathrm{mg} \mathrm{dm})^{-3}\right)$ & 32.82 & 33,10 & 60.50 & 8.20 & 10.87 & 33,14 & -0.513 & 0.230 & 0,1866 & $\mathrm{NO}$ \\
\hline $\mathrm{Ca} 2\left(\mathrm{mmol}_{\mathrm{c}} \mathrm{dm}^{-3}\right)$ & 17.21 & 16.00 & 47.00 & 4.00 & 7.47 & 43.39 & 2.799 & 1.379 & $<0,0001$ & IN \\
\hline $\operatorname{Mg} 2\left(\mathrm{mmol}_{\mathrm{c}} \mathrm{dm}^{-3}\right)$ & 6,53 & 5,00 & 20,00 & 2,00 & 3,93 & 60,14 & 2,274 & 1,426 & $<0,0001$ & IN \\
\hline $\mathrm{K} 2\left(\mathrm{mmol}_{\mathrm{c}} \mathrm{dm}^{-3}\right)$ & 1,02 & 1,00 & 2,20 & 0,10 & 0,35 & 34,37 & 0,588 & 0,454 & 0,0601 & $\mathrm{NO}$ \\
\hline $\mathrm{Al} 2\left(\mathrm{mmol}_{\mathrm{c}} \mathrm{dm}^{-3}\right)$ & 1,50 & 1,00 & 5,70 & 0,00 & 1,22 & 81,35 & 0,436 & 1,038 & $<0,0001$ & IN \\
\hline $\mathrm{H}+\mathrm{Al} 2\left(\mathrm{mmol}_{\mathrm{c}} \mathrm{dm}^{-3}\right)$ & 23,26 & 20,70 & 47,90 & 11,70 & 7,76 & 33,37 & 1,018 & 1,191 & $<0,0001$ & IN \\
\hline $\mathrm{SB} 2\left(\mathrm{mmol}_{\mathrm{c}} \mathrm{dm}^{-3}\right)$ & 24,69 & 22,20 & 67,20 & 7,50 & 11,10 & 44,97 & 3,011 & 1,518 & $<0,0001$ & IN \\
\hline $\mathrm{T} 2\left(\mathrm{mmol}_{\mathrm{c}} \mathrm{dm}^{-3}\right)$ & 48,56 & 47,20 & 84,00 & 26,40 & 12,88 & 26,53 & 0,384 & 0,833 & 0,0001 & IN \\
\hline $\mathrm{V} 2(\%)$ & 50,51 & 49.60 & 80.70 & 15,30 & 13,46 & 26.65 & -0.024 & $-0,040$ & 0.5711 & $\mathrm{NO}$ \\
\hline $\mathrm{m} 2(\%)$ & 7,25 & 5,00 & 35,80 & 0,00 & 7,29 & 100,53 & 3,342 & 1,700 & $<0,0001$ & IN \\
\hline
\end{tabular}

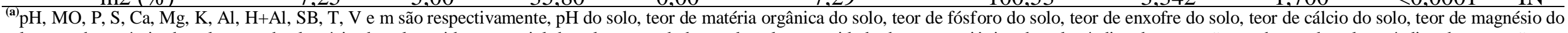

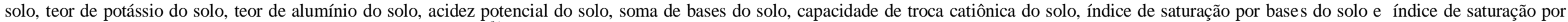
alumínio do solo, coletados nas camadas do solo de $0,25-0,50 \mathrm{~m} ;{ }^{(b)} \mathrm{DF}=$ distribuição de frequência, sendo NO e IN, respectivamente do tipo normal e indeterminado.

Tabela 4. Matriz de correlação entre atributos da cultura da cana-de-açúcar.

\begin{tabular}{|c|c|c|c|c|c|c|c|c|}
\hline \multirow{2}{*}{ Atributos $^{(a)}$} & \multicolumn{7}{|c|}{ Coeficiente de Correlação ${ }^{(b)}$} & \multirow[b]{2}{*}{$\mathrm{pH}$} \\
\hline & PRO & STD & BRI & POL & PUR & FIB & ARC & \\
\hline
\end{tabular}




\begin{tabular}{|c|c|c|c|c|c|c|c|c|}
\hline STD & $0,8742 * *$ & - & - & - & - & - & - & - \\
\hline BRI & $-0,0913$ & $-0,0789$ & - & - & - & - & - & - \\
\hline POL & $-0,1507$ & $-0,1913^{*}$ & $0,6867 * *$ & - & - & - & - & - \\
\hline PUR & $-0,1719$ & $-0,2447 * *$ & $0,1840 *$ & $0,6956 * *$ & - & - & - & - \\
\hline FIB & 0,0324 & 0,0572 & $0,6356 * *$ & $0,4298 * *$ & $0,3283 * *$ & - & - & - \\
\hline ARC & 0,1733 & $0,2453 * *$ & $-0,1828 *$ & $-0,6947 * *$ & $-0,9992$ & $-0,3249 * *$ & - & - \\
\hline $\mathrm{pH}$ & 0,0021 & 0,0451 & $-0,0988$ & $-0,1529$ & $-0,4152 * *$ & $-0,3647 * *$ & $0,4137 * *$ & - \\
\hline ATR & $-0,1553$ & $-0,1960 *$ & $0,6841 * *$ & $0,9987 * *$ & $0,7021 * *$ & $0,4311 * *$ & $-0,7016 * *$ & $-0,1679$ \\
\hline
\end{tabular}

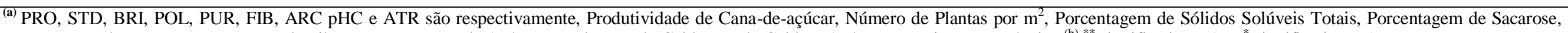

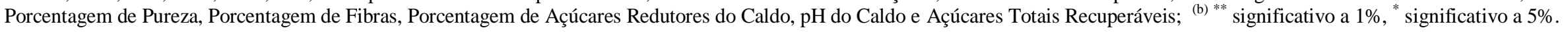

Tabela 5. Matriz de correlação entre atributos da cultura da cana-de-açúcar e atributos químicos coletados nas camadas do solo de 0,00-0,25 m de um Latossolo Vermelho-Amarelo distrófico de Chapadão do Céu, GO.

\begin{tabular}{|c|c|c|c|c|c|c|c|c|c|c|c|c|c|}
\hline \multirow{2}{*}{ Atributos $^{(a)}$} & \multicolumn{13}{|c|}{ Coeficiente de Correlação $o^{(b)}$} \\
\hline & $\mathrm{pH} 1$ & MO1 & $\mathrm{P} 1$ & S1 & Ca1 & $\mathrm{Mg} 1$ & $\mathrm{~K} 1$ & Al1 & $\mathrm{H}+\mathrm{Al} 1$ & SB1 & $\mathrm{T} 1$ & V1 & $\mathrm{m} 1$ \\
\hline pH1 & - & - & - & - & - & - & - & - & - & - & - & - & - \\
\hline MO1 & $0.3679 * *$ & & - & - & - & - & - & - & - & - & - & - & - \\
\hline P1 & $0.5523 * *$ & $0.3991 * *$ & - & - & - & - & - & - & - & - & - & - & - \\
\hline S1 & -0.0621 & -0.1291 & $-0.2596 * *$ & - & - & - & - & - & - & - & - & - & - \\
\hline $\mathrm{Ca} 1$ & $0.8367 * *$ & $0.3541 * *$ & $0.4876 * *$ & -0.0454 & - & - & - & - & - & - & - & - & - \\
\hline Mg1 & $0.8049 * *$ & $0.2810 *$ & $0.4052 * *$ & -0.0262 & $0.8886 * *$ & - & - & - & - & - & - & - & - \\
\hline $\mathrm{K} 1$ & $-0.2179 *$ & 0.0141 & -0.0967 & $-0.2395^{* *}$ & -0.0910 & -0.0935 & - & - & - & - & - & - & - \\
\hline Al1 & $-0.6252 * *$ & $-0.2582 * *$ & $-0.2317^{*}$ & 0.0114 & $-0.5566^{* *}$ & $-0.5354 * *$ & $0.2107^{*}$ & - & - & - & - & - & - \\
\hline SB1 & $0.6884 * *$ & $0.4676 * *$ & $0.4676^{* *}$ & -0.0280 & $0.6603 * *$ & $0.6708 * *$ & $-0.1911^{*}$ & $-0.5200 * *$ & $-0.3493 * *$ & - & - & - & - \\
\hline $\mathrm{T} 1$ & $0.6473 * *$ & $0.3607 * *$ & $0.3111 * *$ & $0.9081 * *$ & $0.9081 * *$ & $0.8412 * *$ & $0.0874 *$ & $-0.4513 * *$ & 0.0273 & $0.5655^{* *}$ & - & - & - \\
\hline V1 & $0.8757 * *$ & $0.2779 *$ & $0.5710^{* *}$ & $0.8238^{* *}$ & $0.8238 * *$ & $0.7910^{* *}$ & $-0.2728 * *$ & $-0.6272 * *$ & $-0.7586 * *$ & $0.7444 * *$ & $0.5637 * *$ & - & - \\
\hline $\mathrm{m} 1$ & $-0.6967 * *$ & $-0.3074 * *$ & $-0.3180^{* *}$ & $-0.6326^{* *}$ & $-0.6326^{* *}$ & $-0.6351 * *$ & 0.1383 & $0.7990 * *$ & $0.3586^{* *}$ & $-0.6559 * *$ & $-0.5364 * *$ & $-0.7558 * *$ & - \\
\hline PRO & 0.0434 & 0.0271 & 0.1628 & -0.0427 & -0.0172 & 0.0080 & 0.1203 & 0.0250 & -0.0820 & -0.0727 & -0.0447 & 0.0209 & 0.0781 \\
\hline STD & 0.0212 & -0.0323 & 0.1231 & 0.0118 & -0.0437 & -0.0101 & 0.0102 & 0.0270 & -0.0672 & -0.0281 & -0.0689 & 0.0114 & 0.0831 \\
\hline BRI & 0.08826 & 0.0619 & 0.0408 & 0.1364 & 0.0606 & 0.0569 & 0.0400 & $-0.1909 *$ & -0.0091 & 0.0168 & 0.0608 & 0.0962 & $-0.2224 *$ \\
\hline POL & 0.1065 & 0.0333 & -0.0735 & $0.1885^{*}$ & 0.0814 & 0.0438 & 0.0545 & -0.1365 & 0.0317 & 0.0047 & 0.0927 & 0.0469 & $-0.1828^{*}$ \\
\hline PUR & 0.0528 & -0.0271 & -0.1462 & 0.1276 & 0.0520 & -0.0037 & 0.0981 & 0.0061 & 0.0566 & -0.0633 & 0.0665 & -0.0299 & -0.0675 \\
\hline FIB & 0.0104 & -0.0696 & 0.0609 & 0.1006 & -0.0181 & -0.0597 & -0.0190 & -0.0124 & -0.1324 & -0.0424 & -0.0916 & 0.0742 & -0.0776 \\
\hline $\mathrm{pHC}$ & 0.0334 & 0.0763 & $0.1828^{*}$ & -0.0625 & 0.0228 & 0.1102 & -0.0797 & -0.0305 & -0.0593 & $0.2062 *$ & 0.0267 & 0.0884 & -0.273 \\
\hline
\end{tabular}




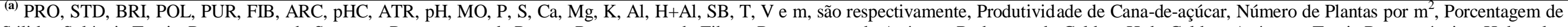

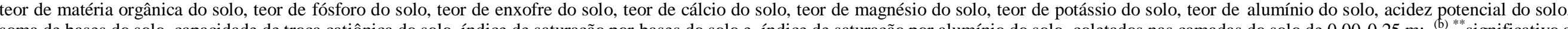
soma de bases do solo, capa

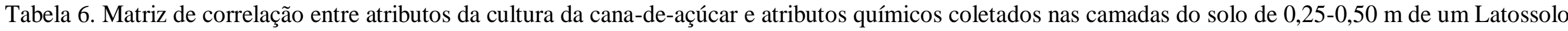
Vermelho-Amarelo distrófico de Chapadão do Céu, GO.

\begin{tabular}{|c|c|c|c|c|c|c|c|c|c|c|c|c|c|}
\hline \multicolumn{2}{|c|}{ AAtri } & \multicolumn{12}{|c|}{ Coeficiente de Correlação ${ }^{(b)}$} \\
\hline untos ${ }^{(a)}$ & $\mathrm{pH} 2$ & $\mathrm{MO} 2$ & $\mathrm{P} 2$ & S2 & $\mathrm{Ca} 2$ & $\mathrm{Mg} 2$ & $\mathrm{~K} 2$ & $\mathrm{Al} 2$ & $\mathrm{H}+\mathrm{Al} 2$ & SB2 & $\mathrm{T} 2$ & $\mathrm{~V} 2$ & $\mathrm{~m} 2$ \\
\hline $\mathrm{pH} 2$ & - & - & - & - & - & - & - & - & - & - & - & - & - \\
\hline MO2 & $0.4481 * *$ & - & - & - & - & - & - & - & - & - & - & - & - \\
\hline P2 & $0.4930 * *$ & $0.4539 * *$ & - & - & - & - & - & - & - & - & - & - & - \\
\hline S2 & $-0.1998 *$ & -0.0977 & $-0.2489 * *$ & - & - & - & - & - & - & - & - & - & - \\
\hline $\mathrm{Ca} 2$ & $0.6960 * *$ & $0.3650 * *$ & $0.3981 * *$ & -0.0397 & - & - & - & - & - & - & - & - & - \\
\hline Mg2 & $0.6749 * *$ & $0.3622 * *$ & $0.4022 * *$ & 0.0691 & $0.9001 * *$ & - & - & - & - & - & - & - & - \\
\hline $\mathrm{K} 2$ & 0.1191 & $0.1929 *$ & 0.1438 & $-0.2033^{*}$ & -0.0048 & -0.0204 & - & - & - & - & - & - & - \\
\hline $\mathrm{Al} 2$ & $-0.7105 * *$ & $-0.3168 * *$ & $-0.2832 * *$ & $0.1793^{*}$ & $-0.4915 * *$ & $-0.4255^{* *}$ & -0.0961 & - & - & - & - & - & - \\
\hline Hal2 & $-0.4067 * *$ & -0.0648 & $-0.3072 * *$ & $0.3259 * *$ & -0.1669 & -0.1667 & 0.1026 & $0.2570 * *$ & - & - & - & - & - \\
\hline SB2 & $0.6912 * *$ & $0.3704 * *$ & $0.3910 * *$ & -0.0242 & $0.9898 * *$ & $0.9424 * *$ & 0.0206 & $-0.4802 * *$ & -0.1635 & - & - & - & - \\
\hline $\mathrm{T} 2$ & $0.3992 * *$ & $0.3094 * *$ & $0.2512 * *$ & $0.2294 *$ & $0.7261 * *$ & $0.7443 * *$ & 0.0888 & $-0.2229 *$ & $0.4410 * *$ & $0.7364 * *$ & - & - & - \\
\hline V2 & $0.7323 * *$ & $0.3154 * *$ & $0.4911 * *$ & -0.1010 & $0.7882 * *$ & $0.7723 * *$ & -0.0753 & $-0.5584 * *$ & $-0.6459 * *$ & $0.7868 * *$ & $0.2894 * *$ & - & - \\
\hline $\mathrm{m} 2$ & $-0.6743 * *$ & $-0.3583^{* *}$ & $-0.3169 * *$ & 0.0956 & $-0.6146 * *$ & $-0.5416^{* *}$ & -0.0624 & $0.9205^{* *}$ & $0.2426 * *$ & $-0.6007 * *$ & $-0.3244 * *$ & $-0.6878^{* *}$ & - \\
\hline PRO & 0.0759 & 0.1733 & 0.1993* & -0.0316 & 0.0974 & 0.0584 & 0.0240 & 0.0669 & $-0.1787 *$ & 0.0962 & -0.0357 & 0.1402 & 0.0486 \\
\hline STD & 0.0441 & 0.1365 & $0.1853^{*}$ & 0.0014 & 0.0968 & 0.0618 & -0.0377 & 0.0483 & -0.1528 & 0.0880 & -0.0228 & 0.1566 & 0.0149 \\
\hline BRI & -0.0224 & 0.1128 & 0.0345 & -0.0221 & -0.0582 & -0.0483 & 0.1006 & -0.0175 & 0.0600 & -0.0553 & -0.0192 & -0.0614 & 0.0212 \\
\hline POL & 0.1131 & 0.0710 & 0.0059 & 0.0742 & -0.0011 & 0.0050 & 0.1604 & -0.0987 & 0.0975 & 0.0055 & 0.0989 & -0.0619 & -0.0242 \\
\hline PUR & 0.1613 & 0.0888 & -0.0666 & 0.0679 & -0.0061 & -0.0338 & 0.1503 & -0.1379 & 0.0548 & -0.0077 & 0.0676 & -0.0860 & -0.0322 \\
\hline FIB & -0.0541 & 0.0230 & 0.0199 & -0.1273 & -0.0858 & -0.1322 & -0.0380 & 0.0434 & -0.1041 & -0.0975 & -0.1764 & -0.0234 & 0.0737 \\
\hline ARC & -0.1565 & -0.0852 & 0.0702 & -0.0660 & 0.0087 & 0.0361 & -0.1538 & 0.1305 & -0.0539 & 0.0102 & -0.0649 & 0.0893 & 0.0255 \\
\hline $\mathrm{pHC}$ & -0.0528 & -0.0196 & 0.0669 & 0.0008 & 0.0056 & 0.0333 & -0.0449 & -0.0541 & -0.0213 & 0.0151 & -0.0453 & 0.0741 & -0.1055 \\
\hline ATR & 0.1147 & 0.0735 & -0.0120 & 0.0835 & -0.0072 & -0.0015 & 0.1573 & -0.0966 & 0.1017 & -0.0010 & 0.0962 & -0.0697 & -0.0200 \\
\hline
\end{tabular}

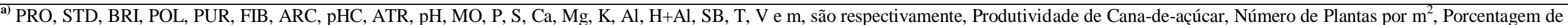

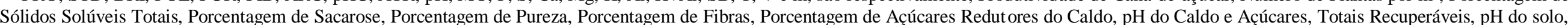

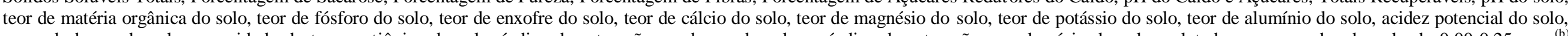

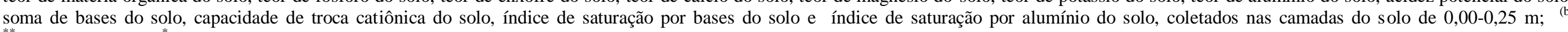
${ }^{* * *}$ significativo a $1 \%,{ }^{*}$ significativo a $5 \%$.

Tabela 7. Parâmetros dos semivariogramas simples e cruzados ajustados para atributos da cultura da cana-de-açúcar e de alguns atributos químicos do solo de um Latossolo Vermelho-Amarelo distrófico de Chapadão do Céu, GO. 


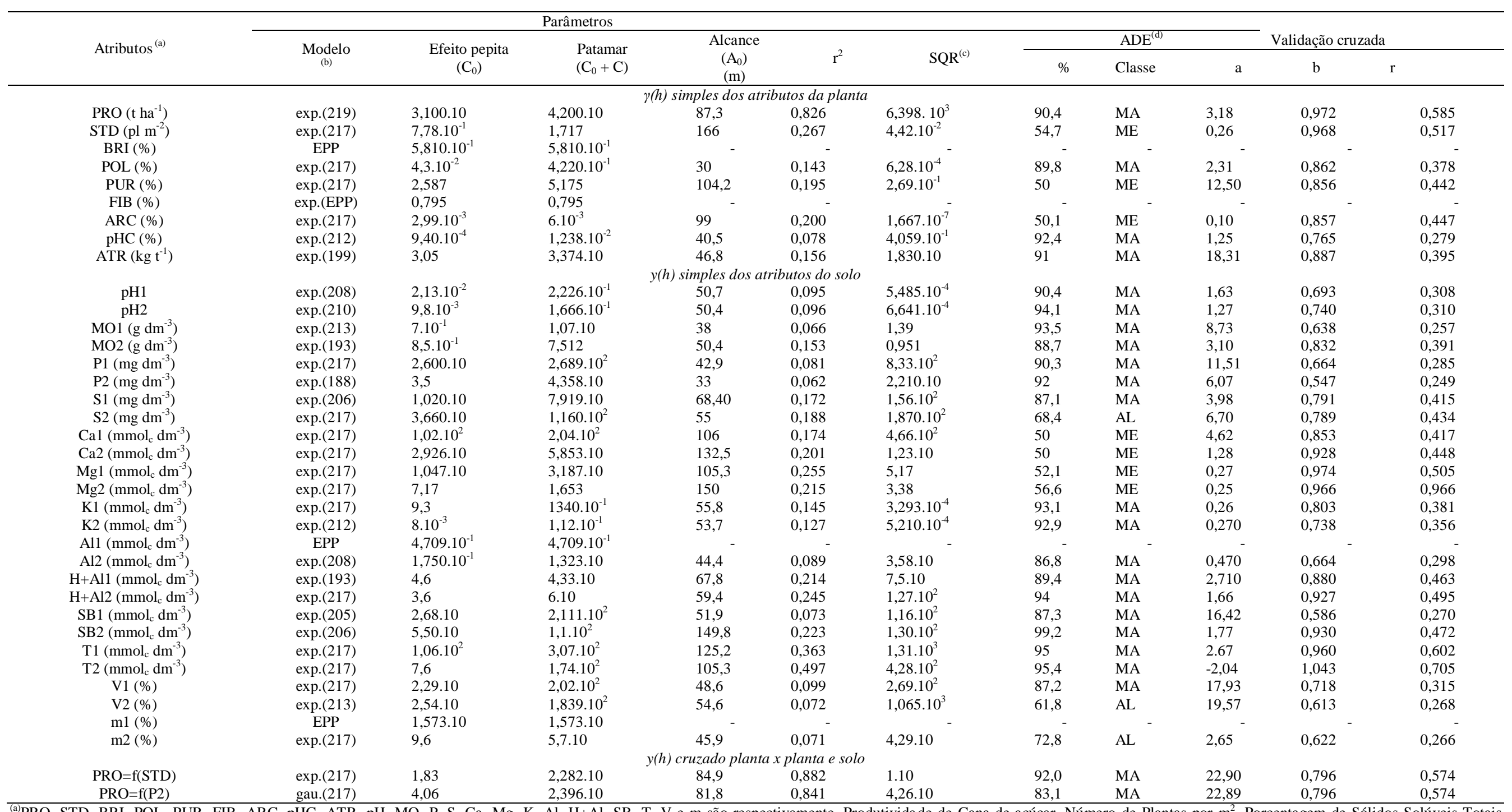

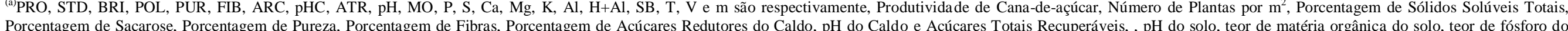

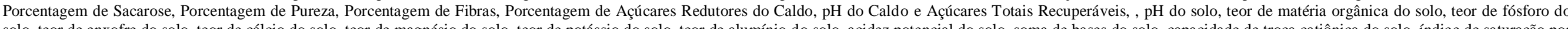

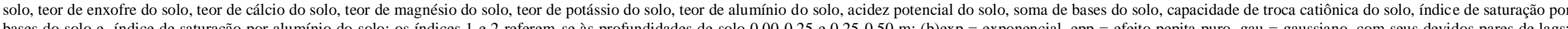

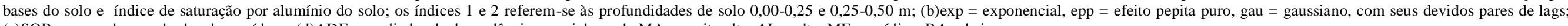
(c) $\mathrm{SQR}=$ soma dos quadrados dos resíduos; (d) $\mathrm{ADE}=$ avaliador da dependência espacial, sendo $\mathrm{MA}=$ muito alta, $\mathrm{AL}=$ alta, $\mathrm{ME}=$ média e $\mathrm{BA}=$ baixo. 


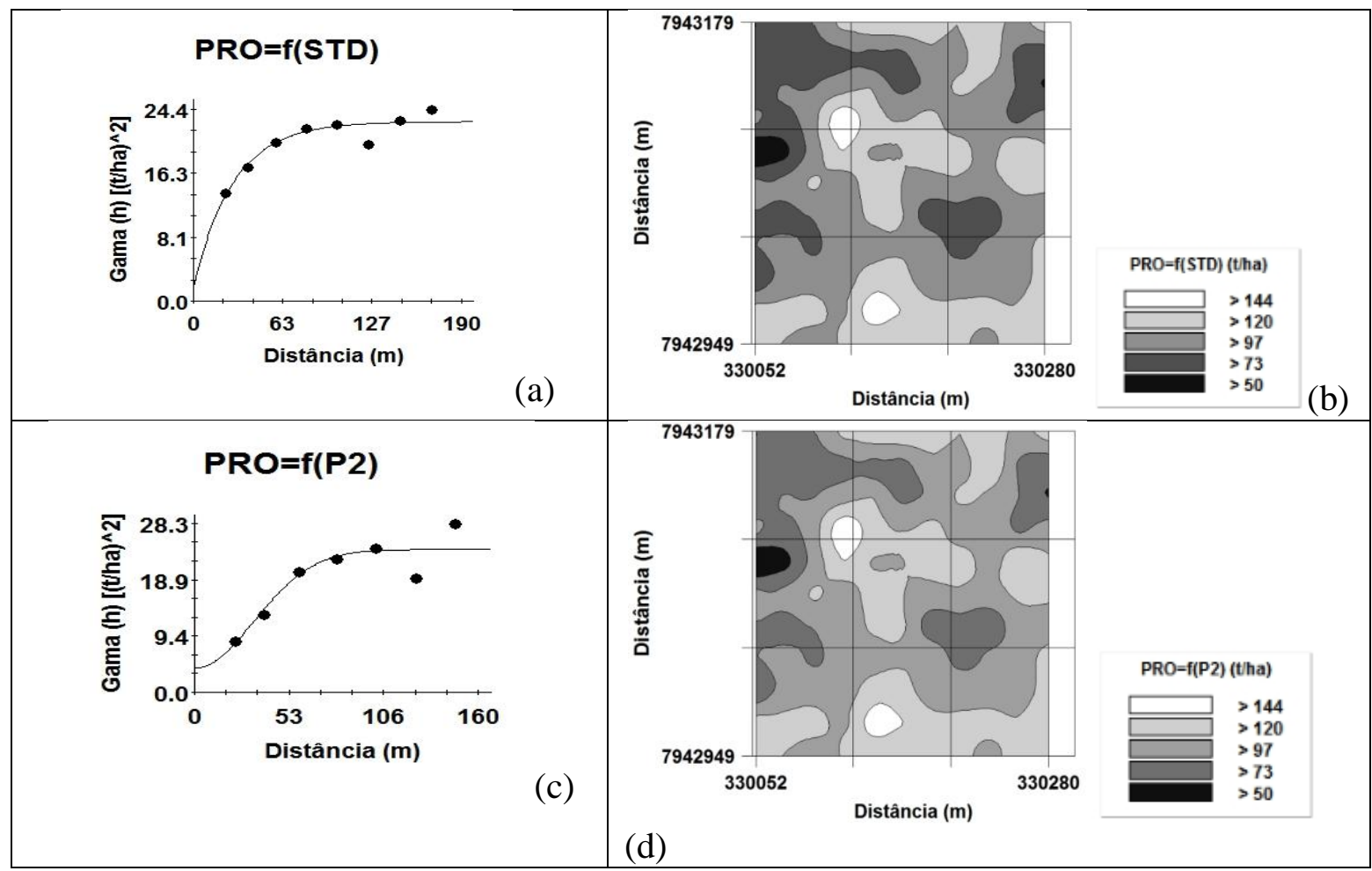

Figura 1. Semivariogramas cruzados e mapas de cokrigagem da PRO em função do STD, PRO em função do P2 de um Latossolo Vermelho-Amarelo distrófico de Chapadão do Céu, GO.

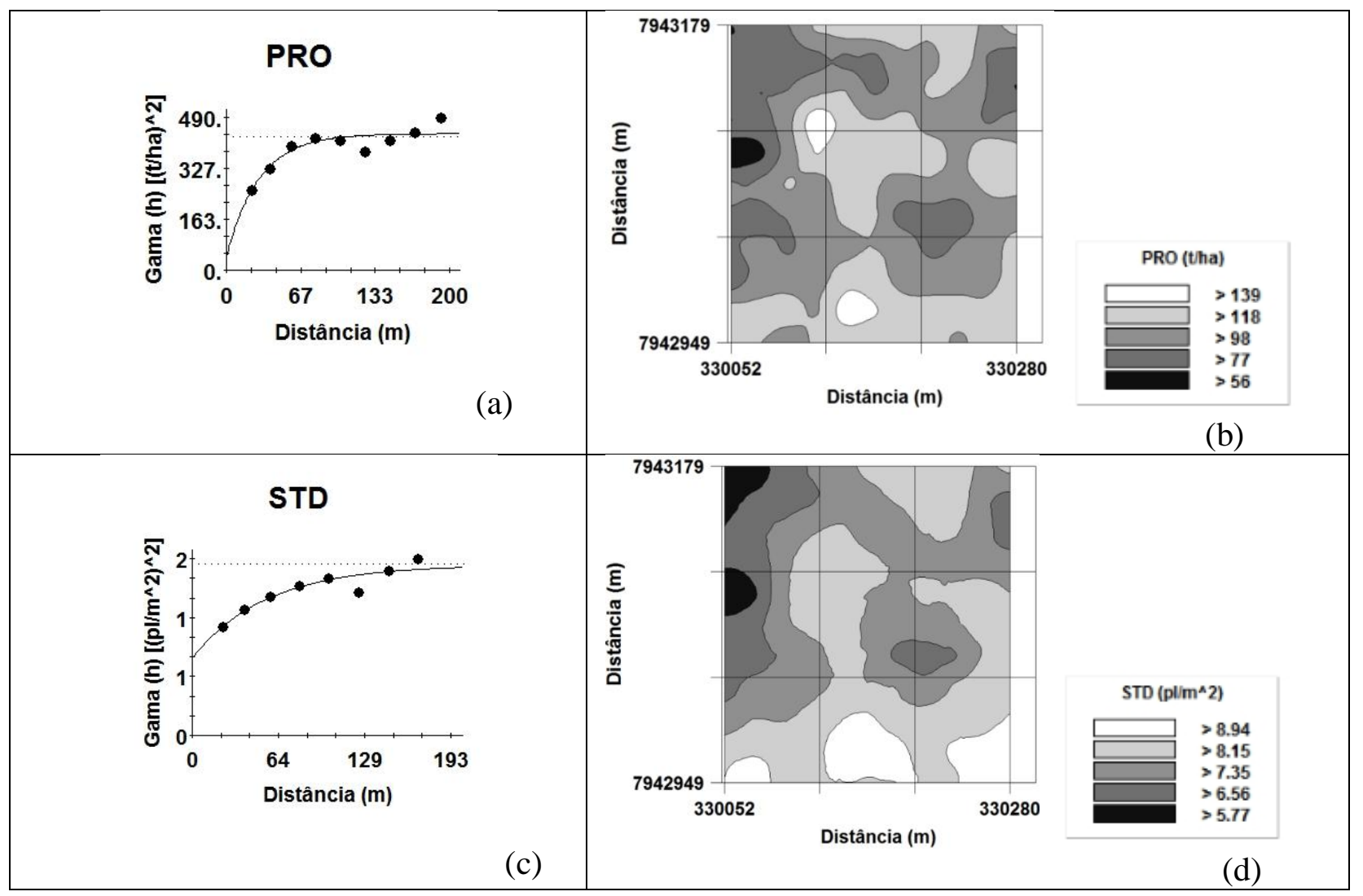




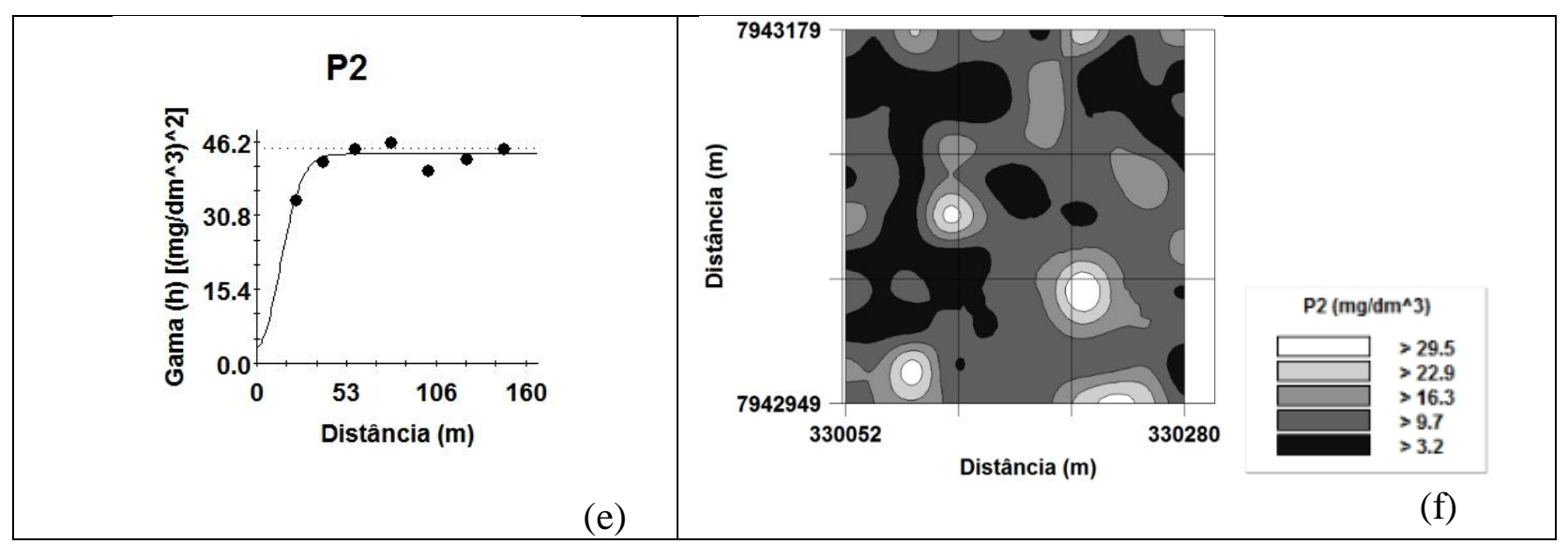

Figura 2. Semivariogramas simples e mapas de krigagem da PRO, do STD e do P2 de um Latossolo Vermelho-Amarelo distrófico de Chapadão do Céu, GO.

Para o ajuste $\mathrm{PRO}=\mathrm{f}(\mathrm{STD})$, pode se observar que $88,2 \%$ da variabilidade espacial da PRO pode ser explicada pela variabilidade do STD. Podendo, a partir dos dados desse atributo, localizar as zonas de manejo para a PRO. Constatando que onde ocorreram os maiores valores de número de plantas por $\mathrm{m}^{2}$ (STD) foram mapeados os maiores valores de PRO (Figura 2b).

Esse comportamento provavelmente pode ser relacionado com o ajuste $\mathrm{PRO}=\mathrm{f}(\mathrm{P} 2)$, segundo Santos et al. (2002) o P desempenha papel importante no crescimento do sistema radicular, bem como no perfilhamento das gramíneas, que são fundamentais à maior produtividade. Sendo assim onde foram encontrados maiores teores de fósforo na profundidade 0,25-0,50 m, ocorreram melhor desenvolvimento nas plantas, resultando assim em maior produtividade. Isto se deve à adubação fosfatada que proporciona aumento de produtividade e do número de perfilhos (CAIONE et al., 2011).

\section{CONCLUSÕES}

Não existiram correlações significativas da produtividade com nenhum dos atributos de fertilidade da primeira camada de solo $(0-0,25 \mathrm{~m})$.

Os teores de fósforo do solo na camada de 0,25-0,50 m e o número de plantas por metro quadrado (stand), por evidenciarem apreciáveis correlações com a produtividade de colmos da cana-de-açúcar $(19,93 \%$ e $87,42 \%)$, foram indicadores de zonas específicas de manejo do solo fortemente associados à produtividade da cana-de-açúcar.

Novas tecnologias de plantio de cana, onde a distribuição das mudas é realizada com precisão, devem contribuir com o aumento de produtividade dos canaviais brasileiros. Visto que $88,2 \%$ da variabilidade espacial da produtividade podem ser explicadas pela variação do stand.

O aumento do atributo estande de plantas está correlacionado em 18,52\% com os teores de fósforo em profundidade.

A matéria orgânica é fundamental para uma boa fertilidade do solo. Sua correlação é positiva e significativa com os principais atributos de fertilidade (P1, P2, Ca1, Ca2, Mg1, $\mathrm{Mg} 2$ e K2), ressaltando a correlação com o fósforo nas duas camadas de 0-0,25 m (39,9 \%) e de $0,25-0,50 \mathrm{~m}(45,4 \%)$. 
Solos do cerrado brasileiro, na maior parte, têm baixos teores de fósforo. Manejos específicos que aumentem o teor de fósforo em profundidade podem contribuir com um melhor perfilhamento e melhores produtividades, visto que $84,1 \%$ da variabilidade espacial do atributo PRO podem ser influenciadas pela variação do atributo P2.

A acidez potencial do solo na camada $0,25-0,50 \mathrm{~m}$ correlaciona negativamente com a produtividade de colmos $(-17,87 \%)$.

\section{REFERÊNCIAS BIBLIOGRÁFICAS}

CAIONE, G.; LANGE, A.; BENETT, C. G. S.; FERNANDES, F. M. Fontes de fósforo para adubação de cana-de-açúcar forrageira no cerrado. Pesquisa Agropecuária Tropical, Goiânia-GO, v. 41, n. 1, p. 66-73, 2011.

CAMARGO, L. A.; MARQUES JUNIOR, J.; PEREIRA, G. T. Mineralogy of the clay fraction of Alfisols in two slope curvatures. III - Spatial Variability. Revista Brasileira de Ciência do Solo, Viçosa-MG, v. 37, n. 2, p. 295-306, 2013.

CARVALHO, L. A.; JUNIOR, C. A. S.; NUNES, W. A. G. A.; MEURER, I.; JÚNIOR, W. S. S. Produtividade e viabilidade econômica da cana-de-açúcar em diferentes sistemas de preparo do solo no Centro-Oeste do Brasil. Revista de Ciências Agrárias, Lisboa, v. 34, n. 1, p. 199-211, 2011.

CERRI, D. G. P.; MAGALHÃES, P. S. G. Correlation of physical and chemical attributes of soil with sugarcane yield. Pesquisa Agropecuária Brasileira, Brasília-DF, v. 47, n. 4, p. 613-620, 2012.

CIRANI, C. B. S.; MORAES, M. A. F. D. Inovação na indústria sucroalcooleira paulista: os determinantes da adoção das tecnologias de agricultura de precisão. Revista de Economia e Sociologia Rural, Brasília-DF v. 48, n. 4, p. 543-565, 2010.

CONAB. COMPANHIA NACIONAL DE ABASTECIMENTO. Acompanhamento da safra brasileira: cana-de-açúcar, segundo levantamento, agosto/2013 - Companhia Nacional de Abastecimento. - Brasília: Conab 2013.

CONSECANA - Conselho dos produtores de cana-de-açúcar, açúcar e álcool do estado de São Paulo -. Manual de instruções. 5. ed. Piracicaba, 2006. 112p.

CORREIA, C. B. G.; AZEVEDO, H. M.; DANTAS NETO, J.; CARVALHO, C. M.; SILVA, L. L.; FEITOSA, S. O. Cana-de-açúcar: parâmetros tecnológicos em função de diferentes lâminas de irrigação e adubação de cobertura. Revista Brasileira de Agricultura Irrigada, Fortaleza-CE, v. 8, n. 1, p. 26-37, 2014.

DALCHIAVON, F. C.; CARVALHO, M. P.; MONTANARI, R.; ANDREOTTI, M.; PANOSSO, A. R. Produtividade da cana-de-açúcar: variabilidade linear e Espacial entre componentes tecnológicos e da produção. Bioscience Journal, Uberlândia-MG, v. 30, supplement 1, p. 390-400, 2014.

DALCHIAVON, F. C.; CARVALHO, M. P.; ANDREOTTI, M.; MONTANARI, R. Variabilidade espacial de atributos da fertilidade de um Latossolo Vermelho distroférrico sob Sistema Plantio Direto. Revista Ciência Agronômica, Fortaleza-CE, v. 43, n. 1, p. 453-461, 2012.

DUTRA FILHO, J. A.; MELO, L. J. O. T.; RESENDE, L. V.; ANUNCIAÇÃO FILHO, C. J.; BASTOS, G. Q. Aplicação de técnicas multivariadas no estudo da divergência genética em cana-de-açúcar. Revista Ciência Agronômica, Fortaleza-CE , v. 42, n. 1, p. 185-192, 2011. 
EMBRAPA. EMPRESA BRASILEIRA DE PESQUISA AGROPECUÁRIA. Sistema brasileiro de classificação de solos. Rio de Janeiro: EMBRAPA Solos. Ministério da Agricultura, Pecuária e Abastecimento. 3 ed., 2013. 353p.

Gamma Design Software (GDS). GS+: Geostatistics for environmental sciences. 7. ed. Michigan, Plainwell: Gamma Desing Software, 2004. 159 p.

KRAVCHENKO, A. N.; ROBERTSON, G. P.; SNAP, S. S.; SMUCKER, A. J. M. Using information about spatial variability to improve estimates of total soil carbon. Agronomy Journal, Madison-USA, v. 98, n. 1, p. 823-829, 2006.

LAVANHOLI, M. G. D. P. Qualidade da cana-de-açúcar como matéria prima para produção de açúcar e álcool. In DINARDO-MIRANDA, L. L., VASCONCELOS, A. C. M., LANDELL, M. G. A. Cana-de-Açúcar (eds.), Campinas-SP: Instituto Agronômico e Fundação IAC, 2008.

MARQUES JÚNIOR, J.; SOUZA, Z.M.; PEREIRA, G. T.; BARBIERI, D. M. Variabilidade espacial de matéria orgânica, $\mathrm{P}, \mathrm{K}$ e CTC de um Latossolo cultivado com cana-de-açúcar por longo período. Revista de Biololgia e Ciências da Terra, v. 8, n. 1, p. 143-152, 2008.

MONTANARI, R.; LIMA, R. C.; BONINI, A. S.; MARQUES, L. S.; MINGUINI, R.; CARVALHO, M. P.; FERREIRO, J.; COSTA, N. R. Variabilidade dos atributos de um Latossolo Vermelho sob plantio direto no cerrado brasileiro e produtividade da soja. Cadernos do Laboratório Xeolóxico de Laxe, La Coruña-Espanha, v. 36, n.1, p. 61-78, 2011.

MONTANARI, R.; PEREIRA, G. T.; MARQUES JUNIOR, J.; SOUZA, Z. M.; PAZETO, R. J.; CAMARGO, L. A. Variabilidade espacial de atributos químicos em Latossolo e Argissolos. Ciência Rural, Santa Maria-RS, v. 38, n. 5, p. 1266-1272, 2008.

MONTANHA, G. K. Agricultura de precisão reduz perdas na lavoura de cana. Revista Campo e Negócio, Uberlândia-MG, v. 9, n. 103, p. 59-73, 2011.

MOLIN, J. P. Agricultura de precisão: o gerenciamento da variabilidade. Piracicaba-SP: O autor, 2001. 83p.

OLIVEIRA, I. R.; TEIXEIRA, D. B.; PANOSSO, A. R.; CAMARGO, L. A.; MARQUES JÚNIOR, J.; PEREIRA, G. T. Modelagem geoestatística das incertezas da distribuição espacial do fósforo disponível no solo, em área de cana-de-açúcar. Revista Brasileira de Ciência do Solo, Viçosa-MG, v. 37, n. 1, p. 1481-1491, 2013.

PIMENTEL GOMES, F. P.; GARCIA, C. H. Estatística aplicada a experimentos agronômicos e florestais. Piracicaba-SP: Brasil. 2002. 309 p.

RAIJ, van B.; ANDRADE, J. C.; CANTARELLA, H.; QUAGGIO, J.A. Análise química para avaliação da fertilidade de solos tropicais. Campinas-SP: Instituto Agronômico, 2001. 285p.

SANTOS, H. Q.; FONSECA, D. M.; CANTARUTTI, R. B.; ALVAREZ, V. H.; NASCIMENTO JÚNIOR, D. Níveis críticos de fósforo no solo e na planta para gramíneas forrageiras tropicais, em diferentes idades. Revista Brasileira de Ciência do Solo, ViçosaMG, v. 26, n. 1, p. 173-182, 2002.

SCAPARI, M. S.; BEUCLAIR, E. G. F. Anatomia e botânica. In: DINARDO-MIRANDA, L. L.; VASCONCELOS, A. C. M.; LANDELL, M. G. A. Cana-de-açúcar. Campinas-SP: Instituto Agronômico e Fundação IAC, 2008. Cap. 2, p. 47-56. 
SCHLOTZHAVER, S. D.; LITTELL, R. C. SAS system for elementary statical analysis. 2. ed. Cary, SAS, 1997. 441p.

SHAPIRO, S. S.; WILK, M. B. An analysys of variance test for normality: complete samples. Biometrika, London, 52:591-611, 1965.

SILVA, M. A. Interação genótipo x ambiente e estabilidade fenotípica de cana-de-açúcar em ciclo de cana de ano. Bragantia, Campinas-SP, v. 67, n. 1, p. 109-117, 2008.

SIQUEIRA, G. M.; VIEIRA, S. R.; CEDDIA, M. B. Variabilidade de atributos físicos do solo determinados por métodos diversos. Bragantia, Campinas-SP, v. 67, n. 1, 203-211, 2008.

SOUZA, Z. M.; CERRI, D. G. P.; COLET, M. J.; RODRIGUES, L. H. A.; MAGALHÃES, P. S. G.; MANDONI, R. J. A. Análise dos atributos do solo e da produtividade da cultura de cana-de-açúcar com o uso da geoestatística e árvore de decisão. Ciência Rural, Santa MariaRS, v. 40, n. 1, p. 840-847, 2010a.

SOUZA, Z. M.; MARQUES JÚNIOR, J.; PEREIRA, G. T. Geoestatística e atributos do solo em áreas cultivadas com cana-de-açúcar. Ciência Rural, Santa Maria-RS, v. 40, n. 1, p. 48$56,2010 b$.

SOUZA, Z. M.; BARBIERI, D. M.; MARQUES JÚNIOR, J.; PEREIRA, G. T.; CAMPOS M. C. C. Influência da variabilidade espacial de atributos químicos de um Latossolo na aplicação de insumos para cultura de cana-de-açúcar. Ciência e Agrotecnologia, Lavras-MG, v, 31, n. 1, p. 371-377, 2007.

SOUZA, Z. M.; MARQUES JÚNIOR, J.; PEREIRA, G.T.; MOREIRA, L. F. Variabilidade espacial do $\mathrm{pH}, \mathrm{Ca}, \mathrm{Mg}$ e V\% do solo em diferentes formas do relevo sob cultivo de cana-deaçúcar. Ciência Rural, Santa Maria-RS, v.34, n. 1, p. 1763-1771, 2004.

VANNI, S. M. Modelos de regressão: estatística aplicada. São Paulo-SP: Legmar Informática \& Editora, 1998. 177p. 